\title{
Resilience: The importance of the long term
}

\section{Résilience : l'importance du long-terme}

\author{
Sander VAN DER LEEUW ${ }^{1}$ \\ ${ }^{1}$ School of Complex Adaptive Systems, College of Global Futures, Arizona State University, vanderle@asu.edu
}

\begin{abstract}
RÉSUMÉ. Le concept de résilience, introduit en 1973, est devenu un outil conceptuel important dans les sciences environnementales, et plus récemment dans l'étude des systèmes socio-environnementaux. Mais il n'est pas aussi répandu en archéologie. Cet article introduit et explique le concept, accentue sa relation avec le paradigme des sciences de la complexité et présente un exemple de son utilisation dans l'interprétation de transformations observées sur le terrain. Son utilité en archéologie est principalement l'étude de la longue durée (siècles ou millénaires), ou les dynamiques concernées sont lentes mais persistantes. Dans de tels cas, le concept de résilience nous permet de développer une description dynamique et relationnelle de l'histoire et de l'émergence de nouveautés.
\end{abstract}

ABSTRACT. The concept of resilience, first introduced in 1973, has become a major conceptual tool in the environmental sciences, and more recently in the study of socio-environmental systems. In archaeology, however, it has not yet found as wide a use. This paper introduces and explains the concept, emphasizes its relationship to the Complex Systems paradigm and presents an example of its application to transformations observed in the field. Its most useful application in archaeology is the study of the long term (centuries or millennia) where the dynamics are slow but persistent. In such cases, it enables a relational and dynamic description of history and the emergence of novelty.

MOTS-CLÉS. Résilience, Système socio-environnemental, Traitement d'information, Panarchie, Système complexe adaptif.

KEYWORDS. Resilience, Socio-environmental system, Information processing, Panarchy, Complex adaptive system.

\section{Introduction: What is resilience}

"Resilience" is a term that, in a relatively short period of about ten years, has become widespread in society, in science, in politics and elsewhere. It is highly relevant in archaeology, but is not as widespread there as one would expect. This paper will argue that it is not only useful in archaeology, but that archaeology can make an important contribution to the concept and the ideas that are associated with it.

The term was first used in materials science, meaning "the ability of a material to absorb energy when it is deformed elastically, and release that energy upon unloading" (Wikipedia, 2020). Somewhat later, the American Psychiatric Association came to define it as "the process of adapting well in the face of adversity, trauma, tragedy, threats, or significant sources of stress" (American Psychological Association, 2012). The most relevant use of the term for archaeologists is the one introduced in ecology by C.S. Holling in a paper in 1973, where its scope was enlarged as follows "[Resilience] is a measure of the ability of [...] systems to absorb changes of state variables, driving variables, and parameters, and still persist" (Holling, 1973 : 17).

Under Holling's leadership, the term spread to a substantive number of environment-related disciplines as part of a major team-building effort funded by the McArthur Foundation in the late 1990's and early 2000's. As a result, several academic institutions created teams of researchers dealing with the topic, of which the most notable is the Stockholm Resilience Center, founded by Carl Folke and Johan Rockström, now directed by Line Gordon. There, a large multidisciplinary team has spent the last twelve years exploring many aspects of socio-environmental system dynamics from a resilience perspective. Their (e-)journal, Ecology and Society is the principal source of publications in this domain. 
More recently, the domain of application of the term has been enlarged again, to systems in general. In that context, it is signifying that, though a resilient system may change as a result of contextual pressures, it does not lose its identity or coherence. In that sense it is applied to human systems, as well as to integrated socio-environmental systems (SES), based on the premise that there is no fundamental separation between environmental and societal subsystems. As McGlade (1995) argues, there is no social (sub)system nor an environmental one; there are only human perceptions of, and actions on, the integrated, dynamic, social and natural environment. One is therefore looking at the resilience of the whole socio-environmental system. But within that system, there is a difference between the societal components and the environmental ones, as the former are able to actively generate changes in the system because they can learn and enable feedback, which the latter cannot.

\section{How does resilience work?}

The driver of the resilience dynamic in Holling's original description is the balance between the flows of information and energy through a system (an organism, a society) (figure 1).

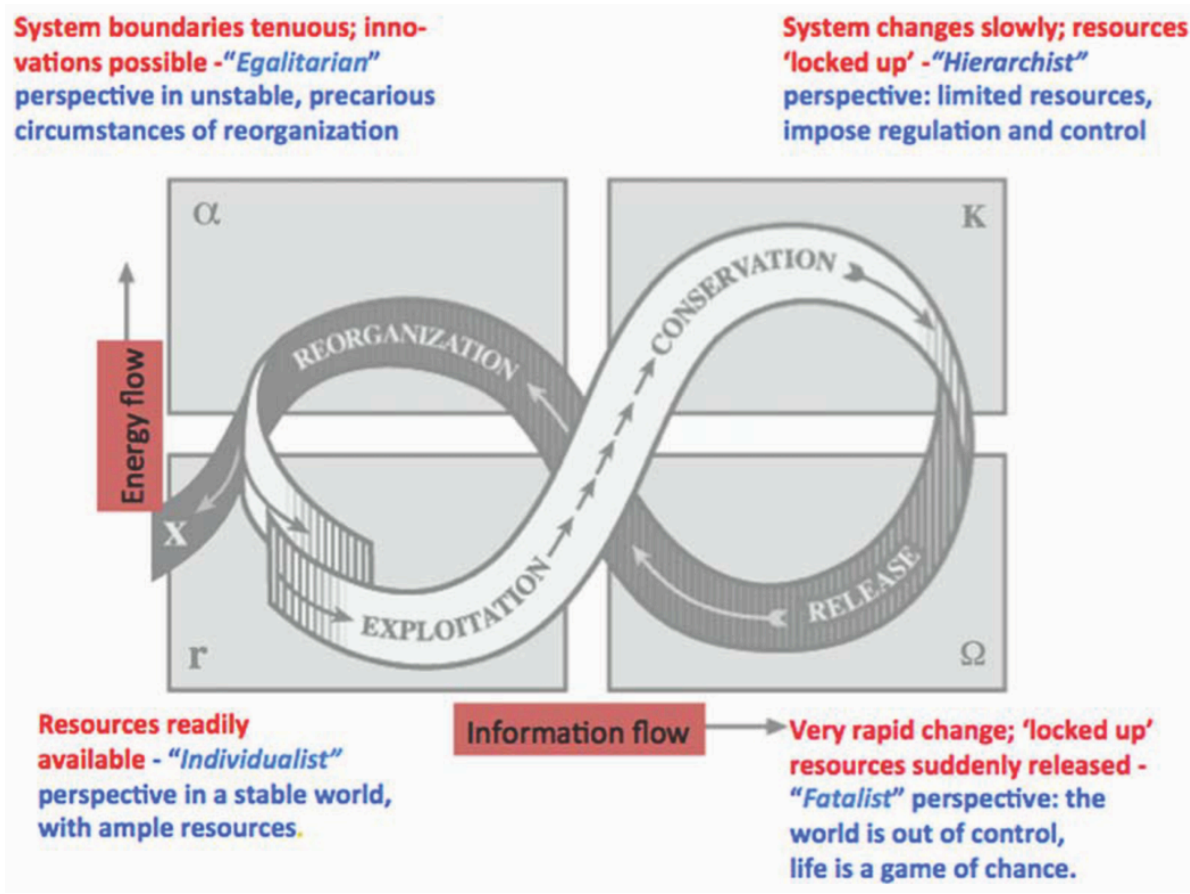

Figure 1. The original environmental resilience diagram proposed by Holling (1973), with (in blue) the human shifts in perspective triggered by systemic change (in red), according to Thompson et. al (1990). For explanation, see text. (C) Original graph published under CC in van der Leeuw (2020)

The underpinning idea is that any organism, group, society or ecosystem depends for its existence on two main flows, one of energy (and matter, which can be converted into energy), and one of information. The flow of information enables the capture and processing of energy that enables the organism's growth and survival. Beginning in phase $\mathbf{r}$, both flows grow by exploiting more and more energy. In the process, innovation is suppressed by the fact that the system's existing feedback loops control its functioning. In phase $\mathbf{K}$, the system approaches the limits to the amount of energy that can be captured with the information available. Then, after a phase of consolidation, the system breaks down into smaller parts, innovation is released, and each of the smaller parts start experimenting with novel kinds of dynamic structures (phase symbol $\mathbf{\Omega}$ ). Ultimately, one or more of these are so efficient that they come to dominate, and the whole system reorganizes around them (phase symbol $\boldsymbol{\alpha}$ ). The system has thus absorbed the necessary changes to re-develop along different lines while retaining its identity.

In a subsequent volume, entitled "Panarchy" (Gunderson \& Holling, 2002), the team added a hierarchical dimension, and called it panarchy, based on the decomposability of complex biological systems into 
different levels, along the temporal dimensions of cycles (cf. Allen \& Starr, 1982). Complex socioenvironmental systems, according to this approach, consist of many levels of dynamics that operate at different clock speeds, but along basically the same dynamic as I have outlined above. By distinguishing these levels, and looking at their interactions, one can identify situations in which the interaction between slower and faster dynamics either anchors and slows down the combination, or accelerates it (cf. figure 2).

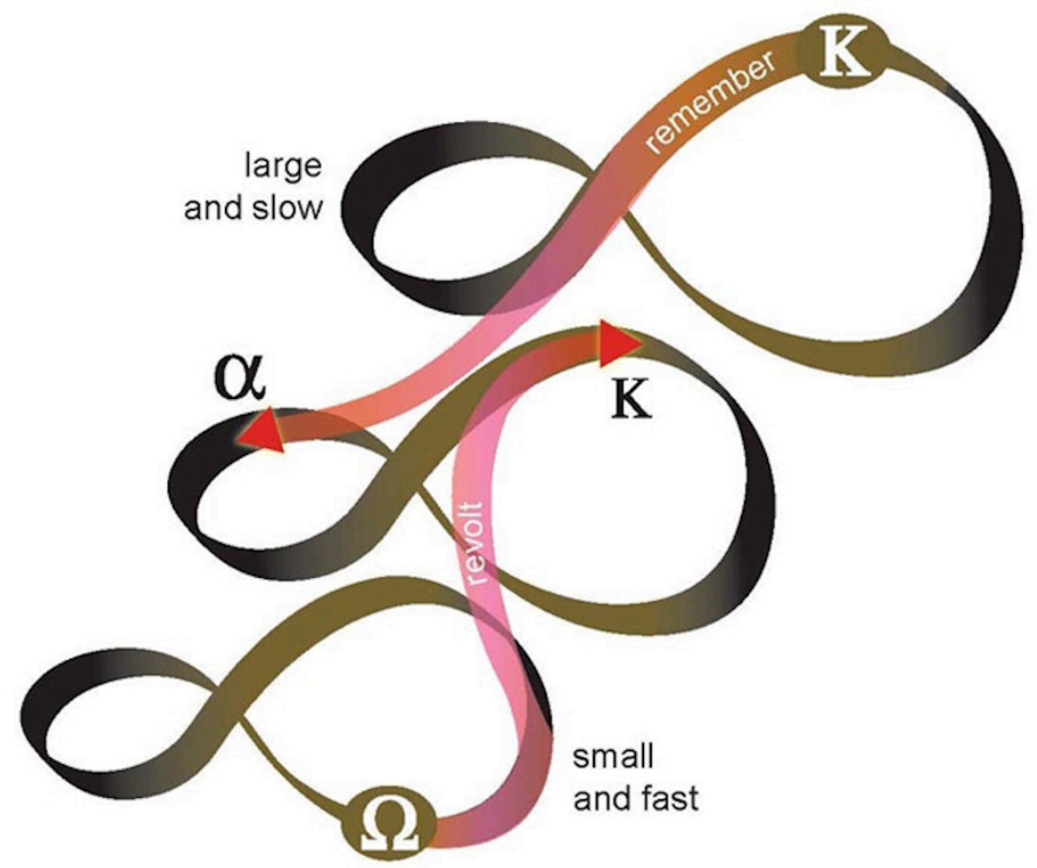

Figure 2. A hierarchical "panarchy" system as proposed by Gunderson \& Holling (2002). In such a complex, multilevel dynamic, the slow dynamics stabilize the fast ones, and the fast ones change the slow ones... For humanimpacted systems we would invert the graph, as the top of a hierarchy processes more information, faster, than the bottom, and the base of a society retains its culture longer.

(C) Adapted from Gunderson \& Holling (2002)

\section{Resilience and Complex Adaptive Systems}

The resilience concept is anchored in the so-called "Complex Adaptive Systems" approach, which is not unlike Bourdieu's (1977) vision of system dynamics, in which a pattern observed at a macro-level (habitus) is deemed to be the result of many interactions at a micro-level (individual behavior), which are themselves partly constrained by the macro-level pattern (habitus) (figure 3). This perspective, which is increasingly adopted in many disciplines, distinguishes itself in many different ways from our current scientific approaches which search ex-post for the origins of present phenomena. Instead, it focuses on identifying exante the emergence of novelty leading to the present.

The word limit, prevents me from going much more deeply into this approach. For that, I recommend Mitchell's (2010) "Complexity: a guided tour". This fundamental paradigm shift, among others, involves the following:

- The inversion of Occam's razor - When faced with different explanatory options, rather than choosing the simplest one, one assumes that systems have too many interacting kinds of dynamics to simplify and looks at more complex explanations.

- Holistic intellectual fusion - rather than disassembling complex phenomena into parts that are supposed to be easier to understand, and then reassembling them to understand the overall complexity, this approach attempts to understand the full complexity of phenomena without disassembling them. The approach is thus fundamentally trans-disciplinary. 
- Rather than as closed and isolated from their context, systems are understood to be open, in interaction and exchange with their environment. They are multi-scalar and multi-temporal.

- Rather than on entities and oppositions, the focus is on relationships, interactions and networks.

- Through time, in this approach, evolution alternates periods of continuity (when the dynamic loop structure is stable) and moments of interruption (tipping points, when the system can reconfigure). There are thus times in which the immediate future follows necessarily from the present, and moments when that is not the case and choices between options occur.

The goal of this approach is learning from the past, about the present, for the future, by an emphasis on using dynamic modeling to understand the evolution of a system.

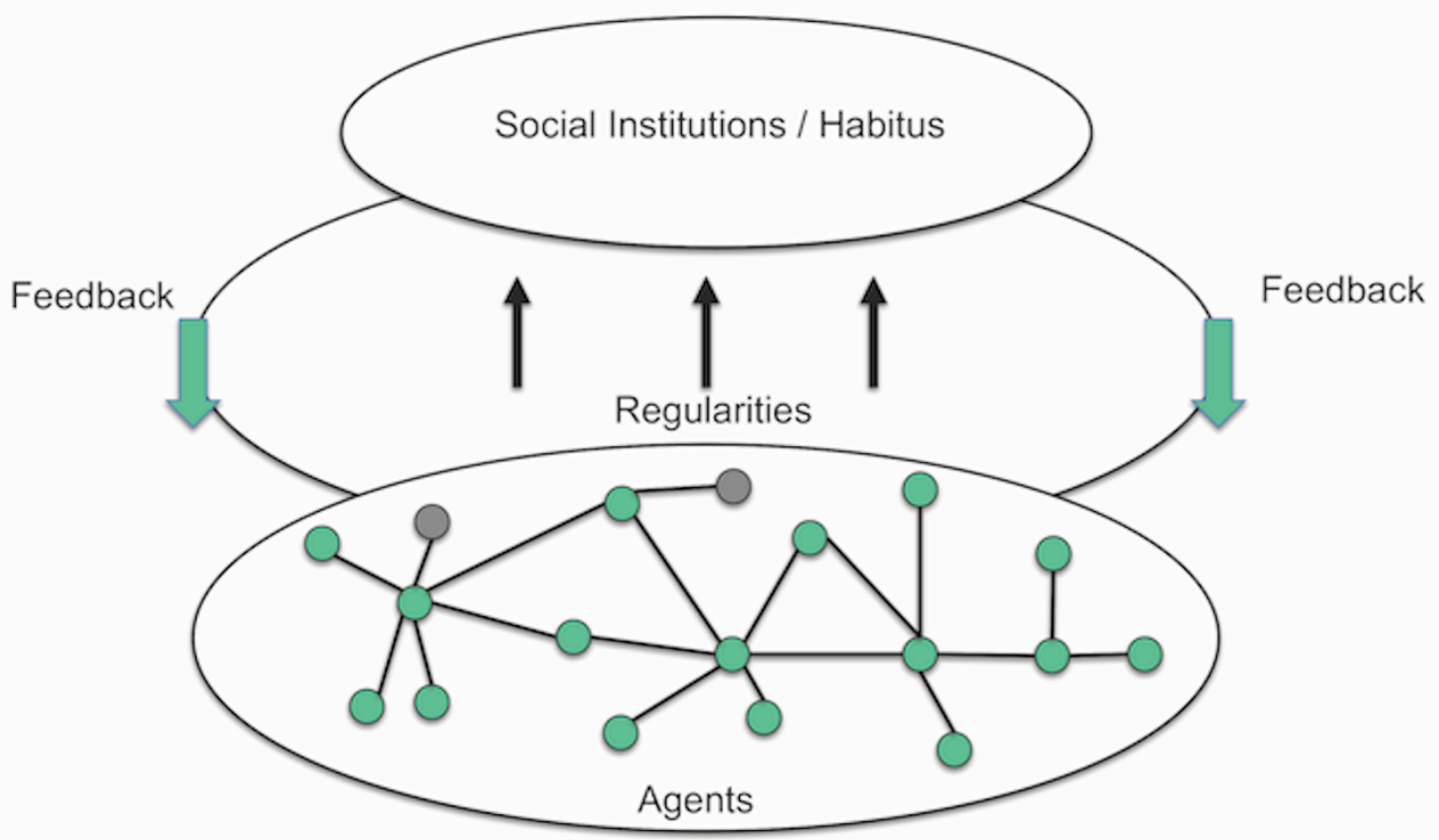

Figure 3. Interactions between individual entities at the lower level create patterns observable at the higher level, which in turn create institutions at the top level, that impact on the interactions between the individual entities at the lower level.

(C) Original graph published under CC in van der Leeuw (2020)

\section{The dynamics of resilience}

In applying this approach to real-world case studies, it is important to keep a few points in mind. First of all, the fact that socio-environmental systems are unstable. They maintain a delicate balance between multiple system states by means of innovation and adaptation.

The more complex the system, the greater the potential for fluctuations at different levels. In a hierarchical system, fluctuations are part-controlled because at each level they operate between slower and faster dynamics at the adjacent levels. Over time, the trajectory is thus a path-dependent one, in which the history of the system plays an important role. Process rates at different levels determine which fluctuations can be controlled by the system, and which cannot.

Over time, systems may have been in operation for such a long time that their information processing hits a tipping point, at which it is no longer able to accommodate environmental change. At such moments system-wide pressure emerges for structural change. In science, such changes are known as paradigm changes. 


\section{Understanding the rural-urban transition}

To illustrate some of these ideas, I will present a simplified description of two system transitions that occurred between WWII and the present in the relatively isolated northwestern part of Epirus (Greece) ${ }^{1}$. I will base that description on the changes in the structure of the information flows in the society. A more extensive analysis of this example can be found in van der Leeuw $(2000,2007,2012)$.

The initial state of the system takes the form of isolated villages, in which everyone knows everything about everyone. Information processing is egalitarian and under universal control because everyone participates on an equal footing. The network is flat, and the information pool homogeneous.

When the overall information flow exceeds certain limits the system transitions is to a state in which information processing is vertically differentiated. Some people process more information than others, know more about what is happening. If they play their role well, they end up in leadership positions and use the network to effectively gather information from all others, and rapidly instruct others in the community when necessary, for example in emergencies. They thus have a degree of control over the society. The information pool is heterogeneous. Such systems are limited in size.

When the hierarchical system is no longer able to efficiently process the information for the growing community, It shifts into a heterarchical state where no one has any control over the whole of the community's information processing. All anyone has is partial information about what is happening, and people make their decisions on that basis. Communities processes information in a combination of hierarchies and horizontal networks. The information pool is homogeneous in its heterogeneity. Such heterarchical systems are unlimited in size.

In Epirus, then, just after WWII, the landscape was one of isolated villages, no roads or motorized transport, mostly local transhumance herding, little agriculture. The communities in the villages were very closed - all information was shared by everyone. Life was dominated by the many slow rhythms of the environment. Humans locked their potentially faster rhythms onto those, slower ones, of the environment, so that change was absent or very slow. Family ties and the sense of community identity were very strong. Contacts and communication was contained in the village, was essentially egalitarian, and developed a homogeneous information pool.

Then two things happened. The British insisted on separating part of Epirus into what became the nation of Albania, and a very violent civil war emerged that divided the region politically. Because there was now a border, there had to be an army to defend it (especially in the cold war), and that army needed asphalted roads to move around in trucks and other motorized vehicles. Because it became much easier to have contacts with other villages and small towns, those roads changed the pattern of information processing. Some people profited from this opportunity, while others did not. Thus, the information circulating in the villages diversified, people differentiated their opinions, creating a more heterogeneous information pool and leading to a loss of village unity.

As part of that process, the tight relationship between the environmental and the societal dynamics began to unravel, because some villagers accorded more value to the societal dynamics, while others maintained their emphasis on the environmental dynamics. This led to a division between the people and villages who wanted to innovate, based on human-designed changes (including technology, and a more exploitative attitude towards the environment), and more conservative ones, who retained their ways of interacting with the environment. Divisive arguments in some villages ensued.

As communication grew among different villages and with the main town, Ioannina, in which the human dynamic was much further developed, this ultimately led, for each village, to the tipping point question: "Do

\footnotetext{
${ }^{1}$ The work on this was done as part of the ARCHAEOMEDES research project funded by DG Research of the European Commission in the early 1990's. The principal researcher was Dr. (now Prof.) Sarah Green at the University of Manchester.
} 
we continue in the old ways, or do we change?". The initial answer was decided by local circumstances, but ultimately, competition led all villages to choose for innovation. The societal dynamics thus overcame the environmental dynamics.

The important difference between the two is that, once dis-embedded from the environmental dynamics, the societal dynamics could accelerate due to the human capacity to learn and change behavior. The latter therefore came to drive the system and led to major modifications in the villages' economies and society. The changes included (1) the villagers' spatial perception of the landscape (from living on the hills and descending to the valleys in winter, to living in the valleys and moving up the mountains in summer), (2) their economies (from sheep- and goat herding on the mountains to raising pigs for sale and growing fodder for them in the valleys), (3) their societal structure (from egalitarian to hierarchical in villages and to heterarchical in urban contexts), (4) their values (less emphasis on family and community coherence, and more on individual success). Markets and small towns emerged in these heterarchical communication networks, principally along the roads.

\section{Resilience in archaeology}

Over much of history, of course, such transitions occurred much slower. The human-environment dynamics of water management in the Western Netherlands are a good example (van der Leeuw, 2012), where human attempts to manage the waters of the North Sea and the Rhine, over a thousand years led to the evolution of the geography, institutions, technology, economy and administrative organization that shape the Western Netherlands today.

Archaeology has a very important role as the only discipline that has the capacity to cover thousands of years, based on a data-set that may be incomplete but is rapidly improving through use of new technologies. It has the further advantage of not being biased by using sources in which the opinion of the author is reflected (van der Leeuw \& Redman, 2002). In today's archaeology, which emphasizes a processual, dynamic approach, the resilience dynamic offers an integrated explanatory model for both trends ( $\mathbf{r}$ to $\mathbf{K}$ ) and tipping points (K to $\mathbf{\Omega})$. It thus also offers a very relevant point of entry into the study of many sustainability challenges.

Among the other advantages that are offered by introducing resilience thinking in archaeological longterm studies, I'd like to emphasize the following:

1. The ability to follow the evolution of socio-environmental dynamics ex-ante with an emphasis on the emergence of novelty, rather than ex-post looking for the origins of the present. We can thus begin to study the past in order to understand the present with an eye on the future!

2. The ability to identify complex combinations of very slow (millennial or centennial) human and environmental dynamics, including processes that were until now undetected. That in turn enables the study of interaction between fast and slow dynamics.

3. The ability to identify and study a much wider range of system states than if one confines oneself to the recent past. In particular, going back a couple of millennia or more in time often allows one to include a system state that was relatively unaffected by human impact. Without that capacity, many sustainability studies can be compared to looking at a very sick patient without knowing what a healthy one may have looked like.

4. The ability to identify and study second order dynamics (changes in the dynamics of change), which are difficult to observe over short timeframes, but which are fundamental indicators of what is going on in a period like the present that is characterized by rapid acceleration of socio-environmental dynamics.

5. The ability to identify and study unintended consequences of earlier (systemic) choices. At any time, a transition from one dynamic structure to another confronts the system with new challenges that it was not 
geared to take into account. In most archaeology, these new conditions are not considered, so that the system's trajectory is described in linear terms, rather than as subject to ontological uncertainty.

Of these new possibilities and challenges, if we desire to improve our understanding of long-term evolutions of socio-environmental systems, the last two are particularly underexploited in the discipline, and merit our attention. And that makes resilience an essential tool in gaining understanding of Earth systems and the co-evolution of humans and their environments.

\section{Conclusion}

This brief summary could not do justice to the topic - for that it has of necessity been too short. Many of the factors driving the two transitions have been omitted, and in particular I have not dealt with the more complex interactions that play a role if the panarchy model is used to describe the evolution. The main argument that I have tried to illustrate is how in two successive transformations, the dynamics of information processing have changed, so that new socio-environmental structures emerged. In this case, those two transitions were compressed into a co-evolution of some 70 years that changed ideas, institutions, spatial organization, communications, the environment and many other things, while maintaining the society's identity. Throughout, I have emphasized how using this approach in archaeology can contribute to developing a dynamic, long-term co-evolutionary perspective on the dynamics of the past.

REMARK. This text is published following its presentation at the session organized by the commission Theory and methods in Landscape archeology - Archeogeography at the XVIII ${ }^{\text {th }}$ Congress of the International Union of Prehistoric and Protohistoric Sciences (UISPP), Tuesday, June 5, 2018 at the University Paris 1 PanthéonSorbonne. The UISPP, founded in 1931, is a member of the International Council for Philosophy and Humanistic Studies, and is associated with UNESCO and the International Academic Union (https://www.uispp.org/).

REMARQUE. Ce texte est publié suite à sa présentation à la session organisée par la commission Theory and methods in Landscape archeology - Archeogeography lors du XVIII ${ }^{\mathrm{e}}$ Congrès de l'Union Internationale des Sciences Préhistoriques et Protohistoriques (UISPP), le mardi 5 juin 2018 à l'Université Paris 1 Panthéon-Sorbonne. L'UISPP, fondée en 1931, est membre du Conseil International de philosophie et de Sciences humaines, et associée à l'UNESCO et à l'Union Académique Internationale (https://www.uispp.org/).

\section{Acknowledgements}

I wish to thank Sandrine Robert (EHESS) for inviting me to the IUSPP session and encouraging me to publish this short paper.

\section{Conflicts of interest}

No conflict of interest to declare. The paper has been prepared by the sole author in his function as professor at Arizona State University

\section{Evaluation}

Reviewers for this paper are Michelle Elliott and Christophe Petit.

\section{Peer-reviewer responsibilities}

Reviewer evaluations are given serious consideration by the editors and authors in the preparation of manuscripts for publication. Nonetheless, being named as a reviewer does not necessarily denote approval of a manuscript; the editors of Archaeology, Society and Environment take full responsibility for final acceptance and publication of an article. 


\section{Bibliographical references}

Allen, T.F.H., Starr, T.B., 1982. Hierarchy: Perspectives for Ecological Complexity. University of Chicago Press, Chicago, $505 \mathrm{p}$.

American Psychological Association, 2012. Building your resilience. https://www.apa.org/topics/resilience, visited on the $25^{\text {th }}$ of March 2021.

Bourdieu, P., 1977. Outline of a Theory of Practice. Cambridge University Press, Cambridge, 256 p.

Gunderson, L.H., Holling, C.S. (Éds.), 2002. Panarchy: Understanding Transformations in Human and Natural Systems. Island Press, Washington DC, $536 \mathrm{p}$.

Holling, C.S., 1973. Resilience and the stability of ecological systems. Annual Review of Ecology and Systematics. 4, $1-23$.

McGlade, J., 1995. Archaeology and the ecodynamics of human-modified landscapes. Antiquity, 69(262), 113-132.

Mitchell, M., 2010. Complexity: a guided tour. Oxford University Press, Oxford, 356 p.

Thompson, M., Ellis, R.J., Wildavsky, A., 1990. Cultural Theory. Westview Press, Boulder, 315 p.

van der Leeuw, S.E., 2000. Land degradation as a socio-natural process, in : McIntosh, R.,Tainter, J. (Éds.), The way the wind blows: Climate, History and human perception. Columbia University Press, New York, 364-393.

van der Leeuw, S.E., 2007. Information Processing and Its Role in the Rise of the European World System, in : Costanza, R., Graumlich, L.J., Steffen, W. (Éds.), Sustainability or Collapse? MIT Press, Cambridge, Mass., 213241.

van der Leeuw, S.E., 2012. Global Systems Dynamics and Policy: Lessons from the distant past. Complexity Economics. 1(2012), 33-60

van der Leeuw, S.E., 2020. Social Sustainability, Past and Future: Undoing Unintended Consequences for the Earth's Survival. Cambridge University Press, Cambridge, 526 p.

van der Leeuw, S.E., Redman, C.L., 2002. Placing anthropology at the center of environmental studies. American Antiquity. 67(4), 597-605.

Wikipedia, 2020. Resilience (materials science). https://en.wikipedia.org/wiki/Resilience (materials science), visited on the $25^{\text {th }}$ of March 2021. 